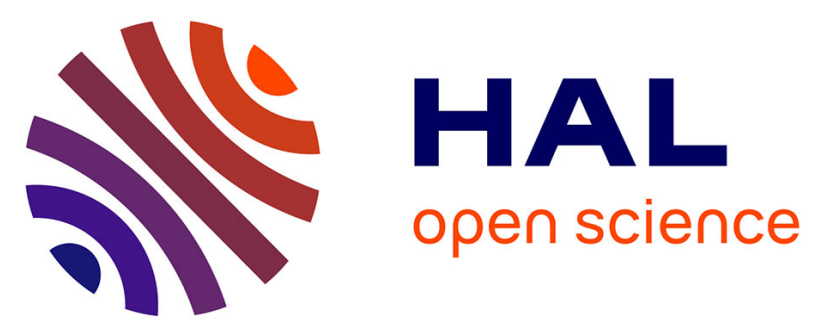

\title{
Perspectives de valorisation d'un milieu par des assolements de grandes cultures : essais d'optimisation technico-économique. I. - Elaboration d'un modèle de choix d'assolement
}

Jean-Robert Marty, Maurice Cabelguenne, Jackie Puech, Alain Hilaire

\section{To cite this version:}

Jean-Robert Marty, Maurice Cabelguenne, Jackie Puech, Alain Hilaire. Perspectives de valorisation d'un milieu par des assolements de grandes cultures: essais d'optimisation technico-économique. I. Elaboration d'un modèle de choix d'assolement. Agronomie, 1984, 4 (9), pp.871-884. hal-00884708

\author{
HAL Id: hal-00884708 \\ https://hal.science/hal-00884708
}

Submitted on 1 Jan 1984

HAL is a multi-disciplinary open access archive for the deposit and dissemination of scientific research documents, whether they are published or not. The documents may come from teaching and research institutions in France or abroad, or from public or private research centers.
L'archive ouverte pluridisciplinaire HAL, est destinée au dépôt et à la diffusion de documents scientifiques de niveau recherche, publiés ou non, émanant des établissements d'enseignement et de recherche français ou étrangers, des laboratoires publics ou privés. 


\title{
Perspectives de valorisation d'un milieu par des assolements de grandes cultures : essais d'opti- misation technico-économique. I. - Elabora- tion d'un modèle de choix d'assolement
}

\author{
Jean-Robert MARTY, Maurice CABELGUENNE \& Jackie PUECH \\ avec la participation d'Alain HILAIRE $\left({ }^{*}\right)$ et la collaboration des techniciens de la Station d'Agronomie \\ I.N.R.A., Station d'Agronomie, Centre de Recherches de Toulouse, B.P. 12, F 31320 Castanet-Tolosan \\ (*) Chambre d'Agriculture de la Haute-Garonne
}

RÉSUMÉ

\begin{abstract}
Des recherches interdisciplinaires, à caractère synthétique, permettent de proposer aux agriculteurs des choix pour la réalisation et l'organisation de rotations et d'assolements, avec ou sans irrigation. Les perspectives de systèmes de culture tiennent compte des aspects technico-économiques. Dans ce premier travail, les auteurs décrivent : la méthodologie utilisée, les données nécessaires pour la réalisation de cette étude et, enfin, l'élaboration du modèle de recherche d'assolements optimisés. Quelques exemples concrets, à partir de caractéristiques typiques du Sud-Ouest de la France, illustrent les possibilités d'interprétation et d'utilisation des résultats issus d'une telle démarche.
\end{abstract}

Mots clés additionnels : Irrigation modélisation, systèmes de culture, rotation, cultures d'été, cultures d'hiver, produit brut, marge brute.

\begin{abstract}
Prospects for increasing the economic value of land using field crops : examples of economic optimization under various technical constraints. I. - Development of a model for choice of land use.

An integrative interdisciplinary research program has led to a scheme which gives farmers options in the arrangement of their rotations and land use, with or without irrigation. Technico-economic aspects were taken into account in evaluating the cropping systems. In this first report, the authors have described the methods used, the data needed, and the development of the model for optimized land use. Several specific examples of data from SW France show how results from the model can be interpreted and used.
\end{abstract}

Additional key words : Irrigation model, cropping systems, rotations, summer crops, winter crops, brut value, gross margin.

\section{INTRODUCTION}

Un système de culture est un sous-ensemble du système de production. Pour une surface de terrain traitée de façon homogène, il est défini par la combinaison des productions végétales avec des voies et des moyens compatibles avec les systèmes d'exploitation et de production choisis. Par voie, on comprend le choix des techniques et de leur succession (itinéraires techniques) et moyens, l'ensemble des apports nécessaires (connaissances, travail, équipement, fournitures, etc....). A cette surface traitée de façon homo- gène, correspond un assolement qui est la répartition annuelle de chacune des cultures occupant les différentes parcelles et une ou plusieurs rotations qui correspondent à l'ordre des successions des cultures (ou jachères) se répétant dans le temps sur une parcelle (Groupe "Système de culture » I.N.R.A.-I.N.A. PG, 1975). Les agronomes, notamment grâce à des expérimentations de longue durée, s'attachent à fournir des références de divers ordres sur les systèmes de culture. Or, l'évolution très rapide des conditions techniques et socio-économiques remet constamment en cause les choix de cultures et de techniques par les agriculteurs. 
De ce fait, il tend à s'établir un décalage ou une inadéquation entre l'offre scientifique ponctuelle et hautement spécialisée et les demandes techniques, économiques et sociales à un niveau plus global (Commission des Communautés Européennes, 1983). Dans son discours d'ouverture des Etats Généraux du Développement Agricole, en 1982, Mme Edith CRESSON, Ministre de l'Agriculture, souhaitait qu'il soit fait « un effort dans le sens du progrès, de la synthèse et de l'adaptation des diverses solutions techniques et économiques proposées aux agriculteurs... ». Un tel effort consiste notamment à fournir des éléments de réponse aux questions suivantes :

- comment proposer aux agriculteurs, à partir de références expérimentales, un choix optimisé de systèmes de culture face à la complexité des systèmes possibles notamment dans les régions qui permettent un large éventail de cultures?

- comment envisager dans une logique d'ensemble les tendances évolutives des systèmes de culture et leurs possibilités d'adaptation face à des contraintes techniques ou économiques plus ou moins rapidement changeantes?

Pour travailler dans cette voie, il est nécessaire de $s$ 'engager dans des recherches interdisciplinaires à caractère synthétique (CAUDERON, 1983). Un contrat programme D.G.R.S.T.-I.N.R.A. (PUECH \& MARTY, 1981) a permis d'instaurer d'étroites collaborations entre agronomes, biométriciens (KAAN \& RELLIER, 1980), économistes (BOUSSARD, 1980) et ingénieurs des Instituts techniques et Organisations professionnelles : Institut Technique des Céréales et Fourrages (ITCF), Centre Interprofessionnel des Oléagineux Métropolitains (CETIOM), Chambre Régionale d'Agriculture du Midi-Pyrénées (CRAMP), Compagnie d'Aménagement des Coteaux de Gascogne (CACG).

L'objectif était donc de proposer aux agriculteurs des solutions pour la réalisation d'assolements et l'organisation des rotations correspondantes et de faire diverses prospectives d'utilisation et de mise en valeur des terres, notamment en présence d'irrigation (ATTONATY, 1969). Pour cela, il fallait que les systèmes de culture proposés soient adaptés aux conditions pédo-climatiques, aux ressources en eau pour l'irrigation, aux disponibilités en matériel et en maind'œuvre, tout en fournissant les meilleurs revenus compte tenu des prix pratiqués; cette dernière exigence, compréhensible, a pour effet d'orienter les choix sur un nombre limité de solutions techniques. De plus, nous voulions apprécier les perspectives d'évolution des assolements et des revenus selon des variations possibles des rapports de prix (augmentation du coût de l'énergie, accroissement du prix des céréales ou des oléoprotéagineux). Nous espérions obtenir un catalogue d'assolements techniquement faisables, économiquement crédibles et agronomiquement justifiés.

Un tel travail a nécessité plusieurs étapes :

- l'acquisition de références expérimentales (périodes 1965-1981) et l'organisation des données ;

- la synthèse générale accompagnée d'observations en exploitations agricoles ;

- l'élaboration d'un modèle de calcul et de choix d'assolements optimisés en complétant les références expérimentales par des hypothèses socio-économiques (capital-matériel, main-d'œuvre et temps d'activité) s'appliquant essentiellement à des exploitations de taille moyenne à caractère familial.

Jusqu'à maintenant, nous nous sommes limités aux assolements et rotations constitués par les grandes cultures à graines commercialisables, soit 4 cultures d'été, maïs, tournesol, soja, sorgho, et 5 cultures d'hiver, blé, orge, colza, pois et/ou féverole.

\section{MÉTHODOLOGIE}

\section{A. Démarche générale}

La méthode utilisée (fig. 1) peut ainsi être subdivisée en 3 niveaux :

- le $1^{\text {er }}$ : étapes de la démarche,

- le $2^{\mathrm{e}}$ : acquisition, organisation et traitement des références expérimentales à la Station d'Agronomie I.N.R.A. d'Auzeville,

- le $3^{\mathrm{e}}$ : apports régionaux et hypothèses formulées pour le passage des rotations aux assolements.

Il est ainsi possible de progresser d'un diagnostic de facteurs limitants biologiques et climatiques à un diagnostic de "goulots d'étranglement » d'ordres techniques et socio-économiques.

Le dispositif expérimental de comparaison de rotations (MARTY \& HUTTER, 1975), d'une part, a permis de 1969 à 1981 d'acquérir un ensemble de données biologiques et agronomiques sur le fonctionnement des cultures et des rotations (fonctions de production eau des cultures d'été, rendements, composantes du rendement, variabilité inter-annuelle, itinéraires techniques pratiqués, calendrier de travaux, arrièreeffets...) qui constituent nos références de base. Cet ensemble de données offre des possibilités de généralisation à partir d'éléments explicatifs (croissance, développement, formation de la production).

D'autre part, divers résultats expérimentaux en différentes localités et types de sol (rendements, techniques pratiquées, eau utilisée, rotations...) ont été rassemblés de 1976 à 1981, en provenance de la CRAMP, de la CACG et des Instituts Techniques. Ces résultats ont permis de vérifier, pour différents lieux et conditions, les perspectives d'application de nos données et d'établir les correctifs nécessaires.

Des contrôles en exploitations agricoles (CACG, 1981 ; CRAMP, 1981) à partir d'une typologie d'exploitations agricoles ont permis de fixer des hypothèses socio-économiques (capital et matériel, maind'œuvre, etc...) qui sont utilisées dans le modèle de calcul et de choix d'assolements.

L'ensemble des données (climat, sol, techniques, production) a été informatisé (banque de données pluriannuelles) grâce à la collaboration avec le Laboratoire de Biométrie I.N.R.A. de Toulouse (KAAN \& RELLIER, 1980).

Ces éléments ont permis d'établir des fiches techniques (MARTY \& HilaIRE, 1974) actualisées en 1981. Celles-ci constituent l'entrée essentielle du modèle de calcul et de choix d'assolements optimisés.

Il a été établi une fiche par culture, par précédent cultural et rotation, par niveau de disponibilité hydrique naturelle, selon que l'on irrigue ou non, et pour 


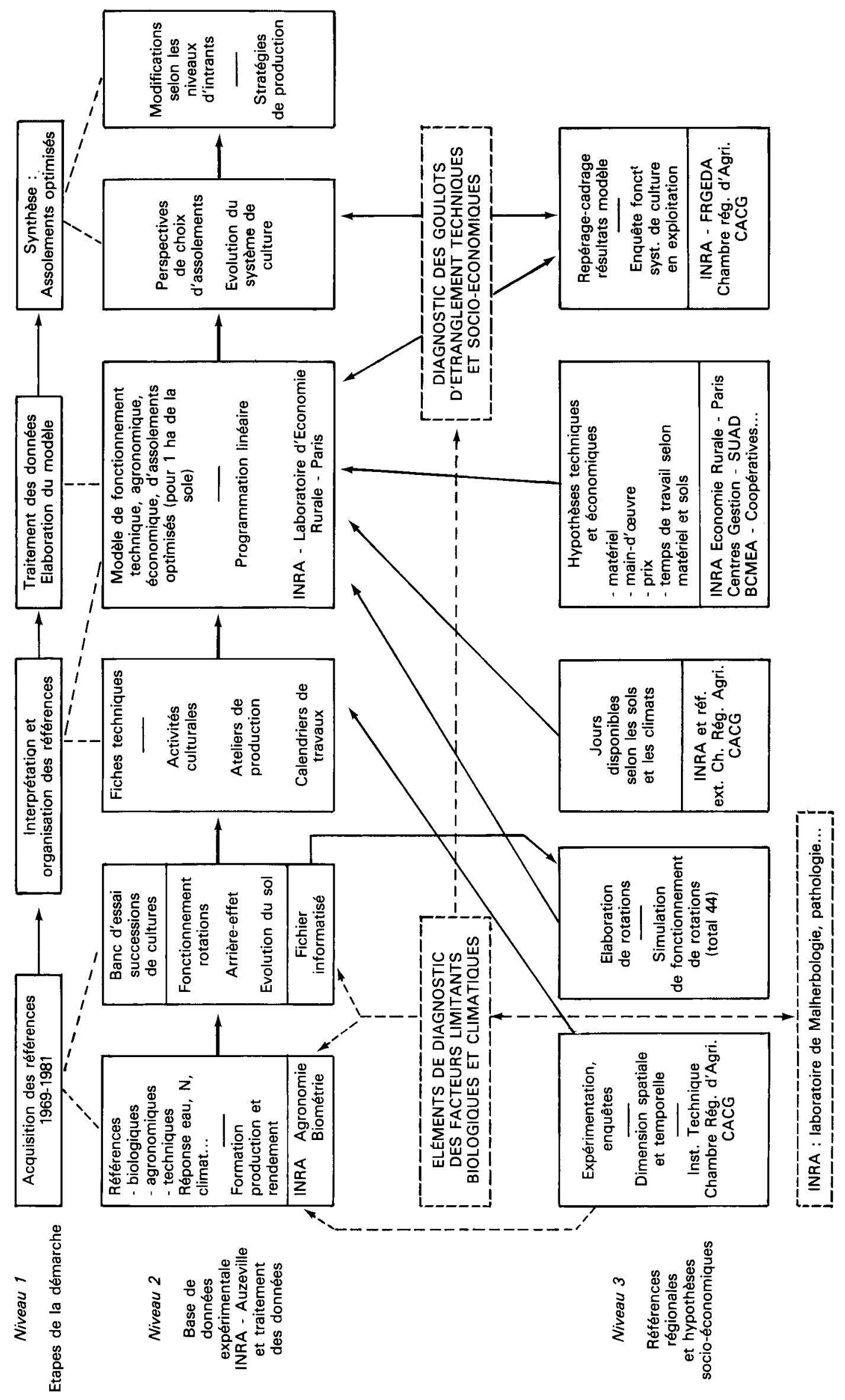

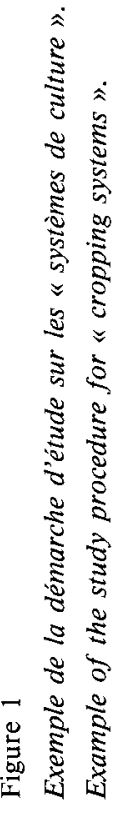


les 2 grands types de sols régionaux (BLANCHET et al., 1966).

Chacune de ces fiches est considérée comme "un atelier de production " avec sa spécificité (BOUSSARD, 1981) dépendant du sous-système «rotation», par exemple, fiches techniques blé après colza, blé après soja, blé après maïs, etc... Pour les cultures d'été, l'effet du précédent cultural est moins net et il n'a pas été retenu.

Enfin, l'apport méthodologique et de calcul très important (BOUSSARD, 1980) a permis de synthétiser ces données sous une forme représentative par l'élaboration d'assolements optimisés, le critère de comparaison étant la marge brute, c'est-à-dire le produit brut moins les charges opérationnelles des cultures.

Cette première partie de notre travail décrit et commente la méthode et les données utilisées, et fournit quelques exemples d'assolements optimisés. Dans la seconde, nous présenterons et discuterons le détail des résultats sur les plans techniques et économiques.

\section{B. Références utilisées}

Elles proviennent, pour l'essentiel, du dispositif expérimental de comparaison de rotations irriguées ou non de l'I.N.R.A. d'Auzeville (sols argilo-limoneux). Ces données ont été complétées par diverses expérimentations provenant des SUAD de Midi-Pyrénées, de la CACG et du CETIOM.

En ce qui concerne les dispositifs I.N.R.A., les cultures d'été et d'hiver combinées en différentes rotations en présence ou non d'irrigation ont été conduites avec pour objectif un bon niveau de rendement et un niveau d'intrants modéré tout en assurant la conservation du sol, et sans facteur limitant essentiel autre que la disponibilité en eau pour les cultures d'été.

\section{Rendement des cultures et variabilité de production}

Les principales références utilisées et leur enchaînement vers des assolements sont :

\section{a) Les cultures d'été (fig. 2A)}

Pour ces cultures, les droites de réponse à l'eau déjà étudiées (MARTY et al., 1975) ont été vérifiées et complétées (CABELGUENNE et al., 1982) et confrontées à d'autres études (FAO, 1980), le progrès génétique pouvant en effet modifier les résultats, comme c'est le cas, par exemple, pour le sorgho (ITCF, 1984). Elles servent de support à la détermination des rendements régionaux des cultures d'été (CABELGUENNE, 1981). La variabilité du rendement a été calculée sur 10 ans à partir des résultats d'Auzeville ou sur 5 ans pour les autres expérimentations (RELLIER, 1981). Pour la suite et pour les cultures d'été, nous utiliserons 3 niveaux hypothétiques de disponibilités hydriques naturelles (CABELGUENNE et al., 1982) provenant des réserves du sol et de la pluie. Pour une pluviométrie estivale moyenne de l'ordre de $180 \mathrm{~mm}$, nous avons retenu comme hypothèses de disponibilités hydriques naturelles totales pour les cultures d'été :

- $270 \mathrm{~mm}$ - sols peu profonds $(40-50 \mathrm{~cm})$;

- $350 \mathrm{~mm}$ - sols moyennement profonds $(80$ $90 \mathrm{~cm})$;

- $420 \mathrm{~mm}$ - sols profonds $(130-150 \mathrm{~cm})$; c'est en moyenne le cas des essais d'Auzeville.
En présence d'irrigation, les rendements moyens dépendent du niveau de disponibilités hydriques naturelles, du nombre d'interventions et des quantités d'eau apportées par l'irrigation qui fixent les quantités d'eau consommée par la culture. On se réfère alors aux droites de réponse à l'eau.

\section{b) Les cultures d'hiver (fig. 2B)}

La moyenne des rendements des cultures d'hiver a été calculée, soit à partir des résultats du dispositif d'Auzeville (sols argileux dits terreforts) (fig. 2B) soit à partir des essais de la CACG et du SUAD de la Haute-Garonne (CACG, 1981 ; Chambre d'Agriculture-SUAD) (sols limoneux dits boulbènes). Les rendements sont légèrement inférieurs en moyenne en sols limoneux battants et sont utilisés dans la partie appropriée du modèle.

La variabilité interannuelle des rendements a été calculée, en ce qui concerne le blé, en tenant compte du précédent cultural et de l'écart-type. Ainsi, les rendements $\mathrm{du}$ blé sont légèrement différents, en moyenne, selon les précédents culturaux (légumineuses, oléagineux, maïs, sorgho) (HILAIRE, 1980), bien que les séries d'interventions divergent techniquement et économiquement (MARTY \& HILAIRE, 1979).

\section{Les itinéraires techniques}

Les résultats présentés ci-dessus ont été obtenus à partir d'itinéraires techniques (SEBILLOTTE, 1978) raisonnés par culture et par rotation. Nous avons noté les dates et nature des interventions, le type de matériel et de produits utilisés, les variétés des différentes espèces étant choisies comme les mieux adaptées à nos conditions expérimentales avec la collaboration des Instituts spécialisés.

\section{a) Les dates et nature des interventions}

A partir des notations réalisées sur le dispositif expérimental d'Auzeville, on a pu établir que, 8 années sur 10, les différentes interventions (travail du sol, semis, traitements, récolte) ont été réalisées entre des intervalles de temps déterminés qui définissent des calendriers probables de travaux.

Dans d'autres conditions de sol (boulbènes), les calendriers de travaux ont été élaborés sur des durées plus courtes (CACG, Revue d'information, 1981; MARTY \& FIORAMONTI, 1970).

\section{b) Le type de matériel et de produits utilisés}

Sur le dispositif expérimental d'Auzeville, a été utilisé du matériel de grande culture mais de type peu performant (tracteur $45-55 \mathrm{cv}$, charrues mono et bisoc, rampes de $9 \mathrm{~m}$, etc...). Au cours des dernières années, nous avons utilisé des produits pesticides récents, et les répercussions possibles sur le rendement sont intégrées dans la moyenne et la variabilité interannuelle. La fertilisation phospho-potassique a été conduite à l'entretien après un enrichissement initial (BLANCHET \& MARTY, 1973 ; BOSC \& BLANCHET, 1976). La fertilisation azotée a été raisonnée en fonction du rendement escompté et du précédent cultural (REMY \& HÉBERT, 1977). 


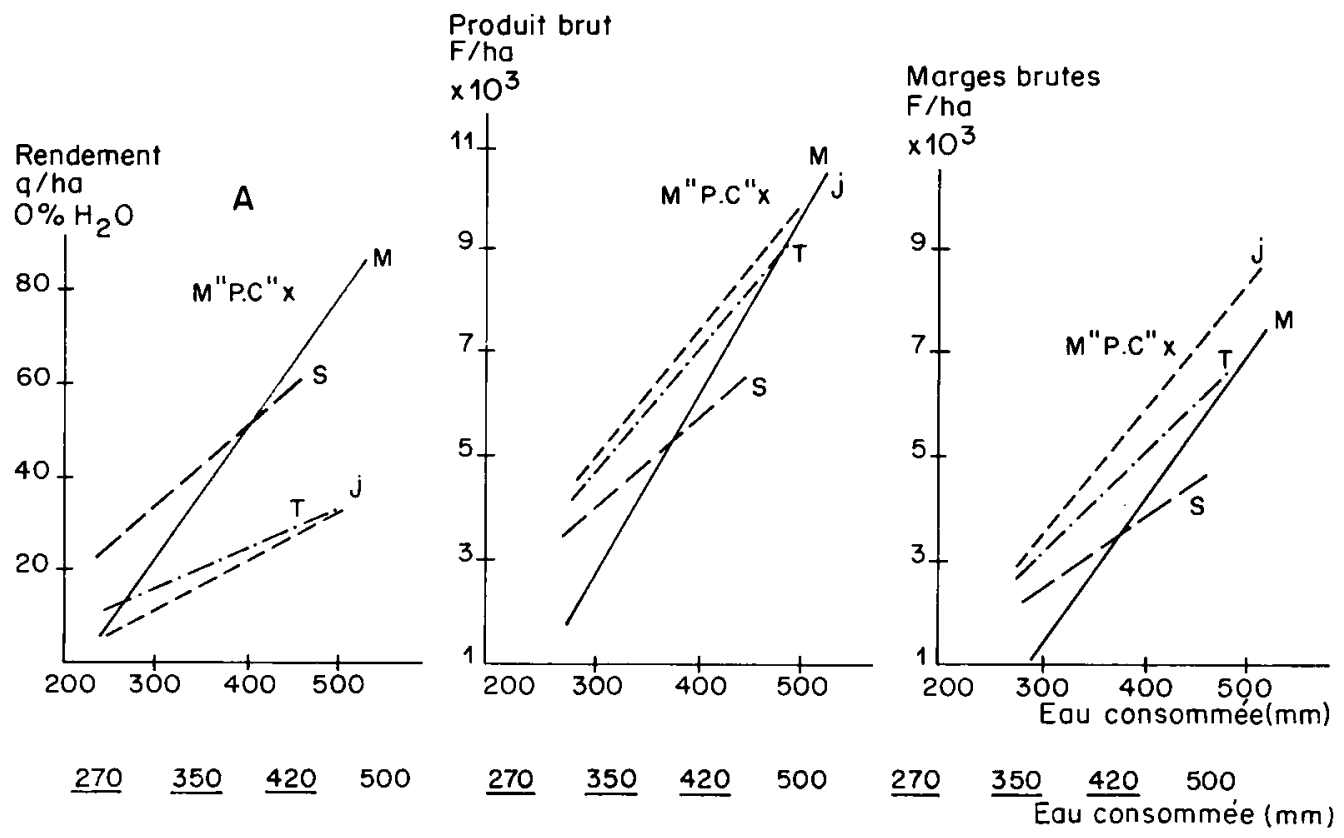

M : Maïs

$M$ «P.C » : Maïs « Période critique »

S : Sorgho

T : Tournesol

$\mathrm{J}:$ Soja
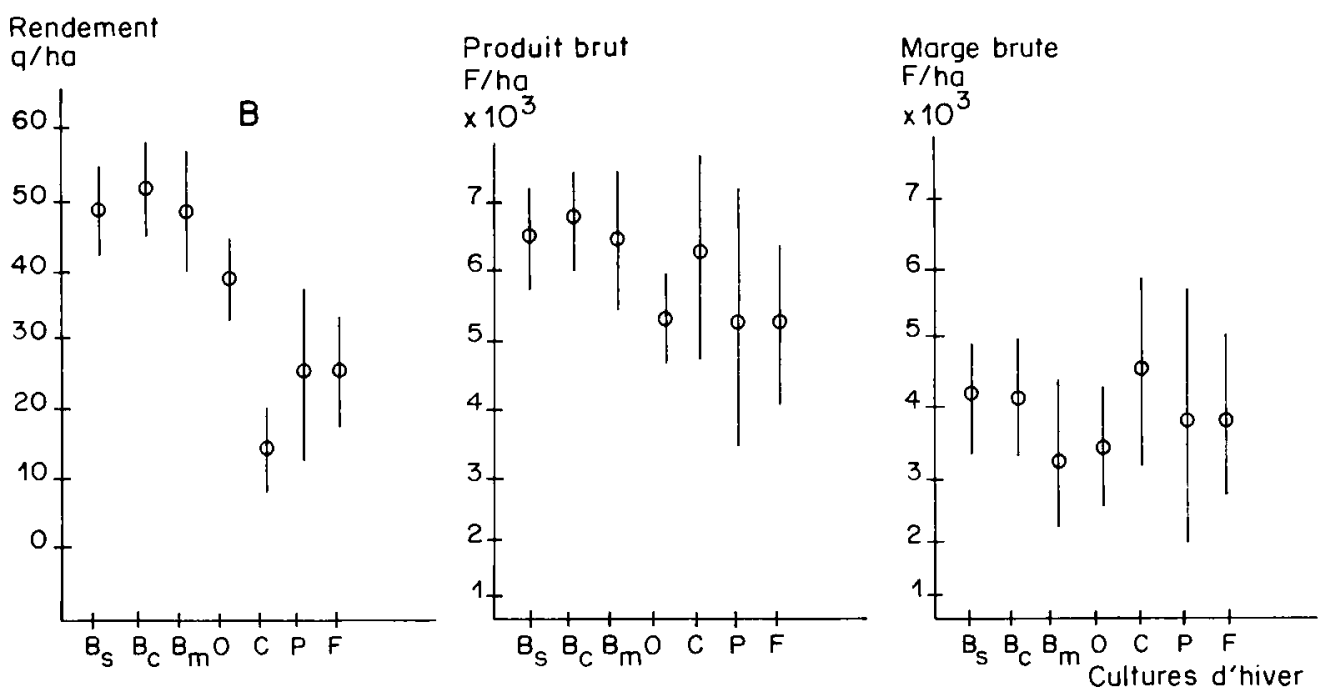

$\mathrm{B}_{\mathrm{s}}$ Blé précédent soja
$\mathrm{B}_{\mathrm{c}}$ Blé précédent colza
$\mathrm{B}_{\mathrm{m}}$ Blé précédent maïs
$\mathrm{O}$ Orge d'hiver

$$
\begin{aligned}
& \text { C Colza d'hiver } \\
& \text { P Pois d'hiver } \\
& \text { F Féverole d'hiver }
\end{aligned}
$$

Figure 2

A. Fonction de production « eau " des cultures d'été : probabilité de production $(q / h a)$, de produit brut et de marge brute $(F / h a)$, prix aux normes 1981-82, en fonction de l'eau consommée ( $\mathrm{mm}$ ).

$B$. Niveau et stabilité de production des cultures d'hiver (moyenne et écart-type); données sur 10 ans, 8 parcelles par culture selon le précédent (sols argilo-limoneux, I.N.R.A., Auzeville).
A. Yield of summer crops in relation to water: probable yield (q/ha), field value and gross margin (F/ha), at 1981-82 prices, in relation to water consumed.

$B$. Level and stability of yield for winter crops laverage and standard deviation) ; 10 years data, 8 plots by crop according to preceding crop (clay soil I.N.R.A., Auzeville). 


\section{Elaboration d'un modèle de recherche d'asso- lements optimisés}

\section{L'outil mathématique : la programmation linéaire}

En collaboration avec la Station d'Economie et de Sociologie rurales de Paris, on a choisi d'utiliser la programmation linéaire pour le calcul d'assolements optimisés (BOUSSARD, 1980). Cette technique déjà mentionnée (LEFORT \& SEBILlOTTE, 1964) et utilisée dans d'autres conditions (SOGREAH, 1965, 1967, 1968) permet une plus grande possibilité de traitement de données que des modèles plus sectoriels dont quelques exemples ont été présentés par ailleurs (DENT \& ANDERSON, 1971) ou de simulation d'assolements proposés a priori (IGER, 1972).

L'intérêt principal de cette technique est de fournir un cadre général d'équations qui représentent un certain nombre de contraintes pesant sur les décisions de l'exploitant. Les équations, une fois écrites, délimitent le domaine disponible à l'intérieur duquel on recherche un point rendant maximale une «certaine fonction économique ». Ce principe d'optimisation permet d'éviter d'être submergé par un trop grand nombre de solutions réalisables entre lesquelles il faudrait choisir. Le modèle utilisé est de très grande dimension, compte tenu des contraintes techniques et économiques de terre, de travail, de capital, de sécurité du revenu, de successions correctes des cultures et des possibilités d'irrigation.

D'après FoUlHoUZE et al., 1981, en ce qui concerne la fonction économique, le fait d'avoir choisi de faire porter l'analyse sur « l'hectare de grande culture " nous imposait pratiquement la maximisation de la marge brute obtenue sur cet hectare. Naturellement, d'autres fonctions économiques (minimisation du temps de travail, maximisation du produit brut, etc...) auraient été envisageables et auraient donné des résultats différents ».

Bien entendu, le plan d'exploitation «optimal» obtenu d'un programme linéaire n'est pas forcément le meilleur possible pour un agriculteur donné. Pour que cela soit vrai, il faut, d'une part, que la matrice des coefficients techniques utilisée traduise effectivement l'éventail des possibilités qui lui sont offertes et les contraintes auxquelles il est soumis; il faut, d'autre part, que les chiffres inscrits (au second membre) reflètent bien la situation de cet agriculteur vis-àvis des contraintes et que la fonction maximisée corresponde bien à ses aspirations. A vrai dire, la programmation linéaire est un cadre général qui doit être rempli d'une façon spécifique pour chaque cas particulier.

Le niveau le plus logique eût été celui de l'exploitation agricole. Cependant, cela eût nécessité l'obtention de renseignements détaillés non seulement sur les «grandes cultures», mais aussi sur les activités de cultures de fourrage et d'élevage qui sont largement pratiquées dans la région. Ces données n'étaient pas disponibles à la Station d'Auzeville. On aurait pu songer à faire une description détaillée de la sole « grande culture » et une description sommaire du reste de l'exploitation. Mais cela n'aurait pas eu beaucoup de sens, puisque les erreurs entraînées par la description grossière des techniques d'élevage se seraient immanquablement répercutées sur les résultats de la sole
" grande culture », dont la précision eût été par conséquent illusoire.

Pour cette raison, il a été décidé de faire porter l'analyse seulement sur la sole « grande culture » et de définir l'unité de décision comme «l'ha de sole grande culture ». Ceci supposait au moins que la possibilité soit donnée à l'exploitant de choisir les quantités de ressources susceptibles d'être affectées à cette sole grande culture. Pour cette raison, plutôt que de résoudre le problème pour différentes « exploitations types ", nous avons combiné systématiquement un " niveau élevé » et un « niveau faible » de chacune des ressources «stratégiques » prises en considération dans notre analyse (fin de citation).

La manipulation d'un tel volume de données a été facilitée par la mise au point d'un générateur de matrice, c'est-à-dire d'un programme d'ordinateur préalable à la programmation linéaire proprement dite et qui traite les données telles qu'elles sont fournies par les informateurs. En particulier, ce programme calcule les marges brutes à partir de prix, de rendements et de consommations unitaires de facteurs de production. Ceci permet d'étudier la sensibilité des solutions à des variations de rapports de prix.

En fait, on a distingué 6 cas de fígure ( 2 types de sol $\times 3$ niveaux de disponibilité hydrique naturelle : $270-350$ et $420 \mathrm{~mm}$, soit 6 programmes linéaires distincts);

La figure 3 schématise la combinaison de cultures d'été et/ou de cultures d'hiver en rotation dont les plus caractéristiques ont été expérimentées sur le dispositif d'Auzeville. La combinaison de rotations en assolements est une synthèse plus complexe liée à des compromis entre différentes contraintes plus directement dépendantes de l'exploitation agricole et du type de sol (travail, matériel, jours disponibles).

La démarche que nous avons suivie a été à la fois inspirée et confortée par des travaux récents (CAPILLON \& SEBILLOTTE, 1980 ; LABONNE, 1980 ; SEGUY, 1980 ) et par des réflexions et discussions avec nos collègues européens au cours des séminaires organisés sur le thème "Système de culture » dans le cadre de l'agriculture méditerranéenne (CEE Agrimed, Séminaires Toulouse 1980 et 1981 ).

2. Contrainte de jours disponibles et de faisabilité des interventions techniques

L'année légale a été divisée en périodes de travaux. Chacune d'elle possède un nombre de jours disponibles (REBOUL et al., 1979) pour les interventions non différables pouvant mettre en jeu le niveau moyen des rendements. La durée de ces périodes est fonction de la quantité et de la diversité des interventions qui peuvent se chevaucher par suite de la combinaison de diverses rotations au niveau de l'assolement. Le nombre moyen de jours disponibles par bloc de travail a été déterminé sur une période de 6 ans en sols argileux à partir du dispositif expérimental d'Auzeville (COCHARD, 1971 ; HUTTER, comm. pers.) et pour les sols limoneux par la CACG et la CRAMP, le tout dépendant des caractéristiques climatiques de la grande région toulousaine.

3. Contrainte de rotations culturales et de successions de culture

Dix rotations culturales ont été expérimentées, de 1969 à 1981, de la monoculture à des rotations de 


\section{A - ROTATIONS $(r)$}

Combinaison des successions de cultures d'été et/ou d'hiver $\left(\mathrm{C}_{1}, \mathrm{C}_{2}, \mathrm{C}_{3}, \ldots\right)$
Niveau de contrainte) (maîtrisable ou non)

\section{Références expérimentales}

(itinéraires techniques, arrière-effet précédent, effet cumulatif rotations...) (sur $\boldsymbol{n}$ années)

$$
B-\operatorname{ASSOLEMENTS}_{(\mathrm{r})}^{(\mathrm{A})}
$$

Combinaison de rotations pour l'occupation annuelle du sol

Recherche d'assolements optimisés

Références expérimentales et hypothèses socio-économiques

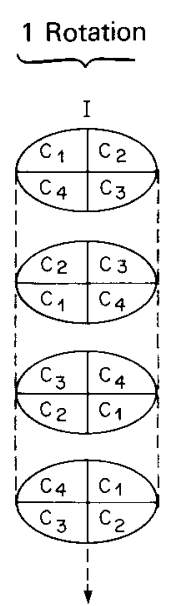

2 Rotations
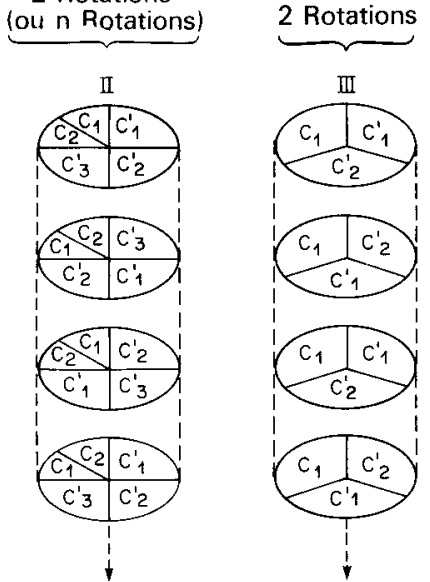

onnées

1ère

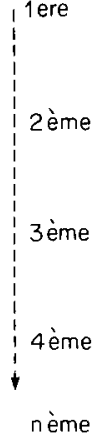

nème
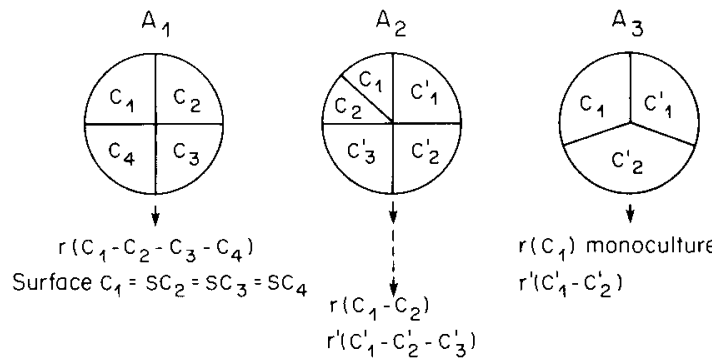

$r\left(C_{1}\right)$ monoculture $r^{\prime}\left(C_{1}^{\prime}-C_{2}^{\prime}\right)$

$\downarrow$

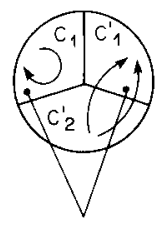

Cultures ponts

Cultures ponts

(passage rotations à successions de cultures)

$\longrightarrow$ d'où $\mathrm{n}$ type d'assolements (n types de rotations)

$(\longrightarrow$ adaptation : compatibilité avec parcellaire)

Figure 3

Exemple de rotations et d'assolements: principes de fonctionnement et recherche d'assolements optimisés en fonction des différents niveaux de contraintes (disponibilités hydriques naturelles, ressources en eau pour l'irrigation, matériel, travail, ...).

6 ans. En même temps, des études ont précisé le fonctionnement de 8 binômes considérés comme un sousensemble de rotation (précédent cultural et culture suivante - arrière-effets ; MARTY et al., 1982c). Ainsi, les successions maïs-blé, soja-blé, colza-blé, sont des binômes culturaux qui peuvent être la rotation ou partie d'une rotation (M-B-S-B). Nous avons pu alors simuler le fonctionnement de 26 autres rotations techniquement et agronomiquement crédibles et fiables pour la région considérée, soit au total une possibilité de choix d'assolements avec 44 rotations. Ce travail a, par ailleurs, exigé la confrontation avec d'autres résultats (FLOCH, 1976 ; DELPHIN \& SPECTY, 1981; RIBEYRE \& MANICHON, 1980). A noter que, parmi ces rotations, existent des «cultures ponts 》 (même culture appartenant à des rotations différentes) (fig. 3) permettant le passage de l'une à l'autre. Le nombre de
Example of rotations and land use : operating principles and search for optimized land use in relation to different levels of constraints (natural water availability, water resources for irrigation, equipment, labour, ...).

successions de cultures possibles devient alors très important et recouvre ainsi la grande diversité révélée par les enquêtes en exploitation agricole.

\section{Hypothèses formulées}

\section{a) Hypothèses de matériel utilisé}

Nous avons retenu 2 hypothèses de matériel utilisé, performant ou peu performant, en partant de l'équipement nécessaire à une exploitation familiale de 40-50 ha. A chaque type de matériel correspond un niveau d'investissement en capital et en charges d'amortissement, calculé d'après la liste de matériel nécessaire pour les systèmes de culture envisagés, à environ 4000 ou $1000 \mathrm{~F} / \mathrm{ha} / \mathrm{an}$. Selon l'utilisation de l'un ou l'autre de ces types de matériel en sols argileux ou limoneux, les temps de travaux sont différents (fichier Régional). Toutefois, le programme de calcul 
permet l'utilisation de l'un et/ou l'autre de ces matériels dans la limite du capital disponible. Dans le cas de faible niveau en capital ( $1000 \mathrm{~F} / \mathrm{ha} / \mathrm{an})$, s'il y a parfois utilisation de matériel performant, on peut supposer qu'il s'agit par exemple d'une activité en CUMA (Coopérative d'Utilisation de Matériel Agricole). Pour l'irrigation, ont été retenus soit un dispositif en couverture totale, soit l'enrouleur avec canon, avec des périodes et des temps d'installation et d'utilisation différents.

\section{b) Hypothèses de main-d'œuure}

Sur la base d'une exploitation à main-d'œuvre familiale, nous avons considéré 2 cas : soit une faible disponibilité en main-d'œuvre équivalente à $21 \mathrm{~h} / \mathrm{ha} / \mathrm{an}$, soit une forte disponibilité de $40 \mathrm{~h} / \mathrm{ha} / \mathrm{an}$ avec, dans chacun d'eux, la possibilité de travailler $12 \mathrm{~h} /$ jour en période de pointe.

\section{c) Hypothèses de ressources en eau d'irrigation}

Nous avons retenu 3 niveaux de ressources en eau pour l'irrigation, 500, $1500,2500 \mathrm{~m}^{3} / \mathrm{ha} / \mathrm{an}$, sans pouvoir dépasser, techniquement $1000 \mathrm{~m}^{3} / \mathrm{ha} / \mathrm{mois}$ (CACG, 1981) pour les fortes ressources. Le niveau le plus élevé $\left(2500 \mathrm{~m}^{3} / \mathrm{ha} / \mathrm{an}\right)$ correspond à des ressources en eau non limitantes dans nos conditions climatiques moyennes. Il s'agit de quantités d'eau théoriquement disponibles au niveau de l'exploitation qui pourront être plus ou moins utilisées ou concentrées sur certaines cultures selon les conditions d'optimisation de l'assolement.

\section{d) Hypothèse de sécurité de revenu}

Sur la base des écarts-types à la moyenne des rendements, nous imposerons dans le calcul de recherche d'assolement en présence d'irrigation, que le revenu ne peut être inférieur à un certain niveau $(3000 \mathrm{~F} /$ ha/an) plus d'une année sur 5 dans le cas de systèmes irrigués.

\section{e) Hypothèses d'évolution des prix}

Les calculs sont faits avec les prix en vigueur en 1981-1982. Nous avons ensuite calculé les évolutions des assolements optimisés selon un accroissement du coût de l'énergie de 20 p. 100 (celui-ci a doublé de 1979 à 1981), ou une diminution relative de 20 p. 100 du prix des céréales ou au contraire des oléoprotéagineux.

\section{EXEMPLE DE RÉSULTATS ET DISCUSSION}

\section{A. Fonctionnement du modèle de recherche d'asso- lements optimisés}

\section{Application à deux types de sols régionaux}

La figure 4 schématise la conception du modèle technico-économique. Pour les 2 types de sol, on obtient ainsi 672 possibilités (l'hypothèse de sécurité de revenu ne s'appliquant qu'aux systèmes irrigués).

Parmi l'ensemble des résultats, nous présenterons un tableau récapitulatif, fourni par l'ordinateur, d'un assolement optimisé pour illustrer quelques possibilités de sortie et d'utilisation (fig. 5). Nous y trouverons, pour les hypothèses prises en compte, les marges brutes maximales à l'ha assolé et les éléments constitutifs du système par culture, par rotation, par assole- ment (un autre tableau, non présenté ici, fournit, par bloc de travaux, la quantité de main-d'œuvre, le type de matériel et les temps d'utilisation). Les perspectives d'assolements optimisés constituent une $1^{\text {re }}$ étape qui doit être suivie de l'analyse et de l'interprétation de ces résultats et de leur possibilité d'utilisation, notamment comme aide aux choix de l'agriculteur. Les assolements ainsi optimisés seront confrontés à ceux réalisés dans des exploitations agricoles dont certains critères de choix, liés à une logique interne à l'exploitation, n'ont pas été directement pris en compte ici (CACG, 1982).

\section{L'interprétation peut être faite à 2 niveaux :}

- L'un global, cherchant à connaître l'influence de différents rapports de prix sur l'évolution possible de systèmes de culture optimisés, soit par la fréquence et la proportion des cultures dans les assolements (MARTY et al., 1983a ; MARTY et al., 1982a, 1983b), soit par l'effet d'une technique modifiant les intérêts respectifs des cultures d'été et des cultures d'hiver, comme par exemple l'irrigation (MARTY et al., 1982b).

- L'autre, détaillé, en analysant les effets respectifs sur l'optimisation des assolements, du type de sol, des disponibilités hydriques naturelles, des ressources en eau pour l'irrigation, des possibilités en équipement et en main-d'œuvre, des exigences de sécurité de revenu comme le schématise la figure 6 . Ainsi, par exemple, sur le choix des assolements et la possibilité plus ou moins grande d'adaptation à la conjoncture économique, il ressort l'importance des jours disponibles pour réaliser les interventions techniques, compte tenu du matériel et de la main-d'œuvre dont on peut disposer. Ces aspects seront présentés dans une prochaine note.

\section{B. Test de sensibilité du modèle}

Il ne serait pas crédible de proposer un système de culture optimisé qui serait radicalement modifié par une faible variation de l'un des paramètres du modèle.

Nous avons donc choisi de faire varier progressivement la disponibilité en main-d'œuvre entre les 2 hypothèses précédemment formulées, de 20 et $40 \mathrm{~h} / \mathrm{ha} / \mathrm{an}$, et de suivre l'évolution des proportions des différentes cultures et du résultat économique (fig. 7). Nous avons opté pour la contrainte de maind'œuvre parce qu'elle apparaît importante dans le choix des assolements.

En l'absence d'irrigation, les proportions des différentes cultures (B) et les résultats économiques (A) restent stables à partir de $24 \mathrm{~h}$ disponibles/ha/an, et les assolements proposés sont limités à partir de ce seuil par le manque de ressources en eau complémentaire.

En système irrigué, ces proportions évoluent progressivement avec l'augmentation de main-d'œuvre par un accroissement des cultures d'été (maïs, soja) et une diminution des cultures d'hiver (blé, colza). Contrairement au cas précédent, le palier maximum de marge brute n'est pas atteint, même avec l'hypothèse haute de disponibilité en main-d'œuvre, ce qui confirme la nécessité de disposer d'importantes possibilités en main-d'œuvre pour profiter pleinement de l'irrigation en système de grande culture, à moins que 
A. Schématisation de la démarche Type de sol :

Disponibilité hydrique naturelle pour les cultures d'été $(\mathrm{mm})$

Avec ou sans irrigation

Ressource en eau pour l'irrigation

\section{Hypothèse}

Capital - matériel

\section{Hypothèse}

Main-d'œuvre

\section{Hypothèse}

Sécurité du revenu

Solutions d'assolements optimisés

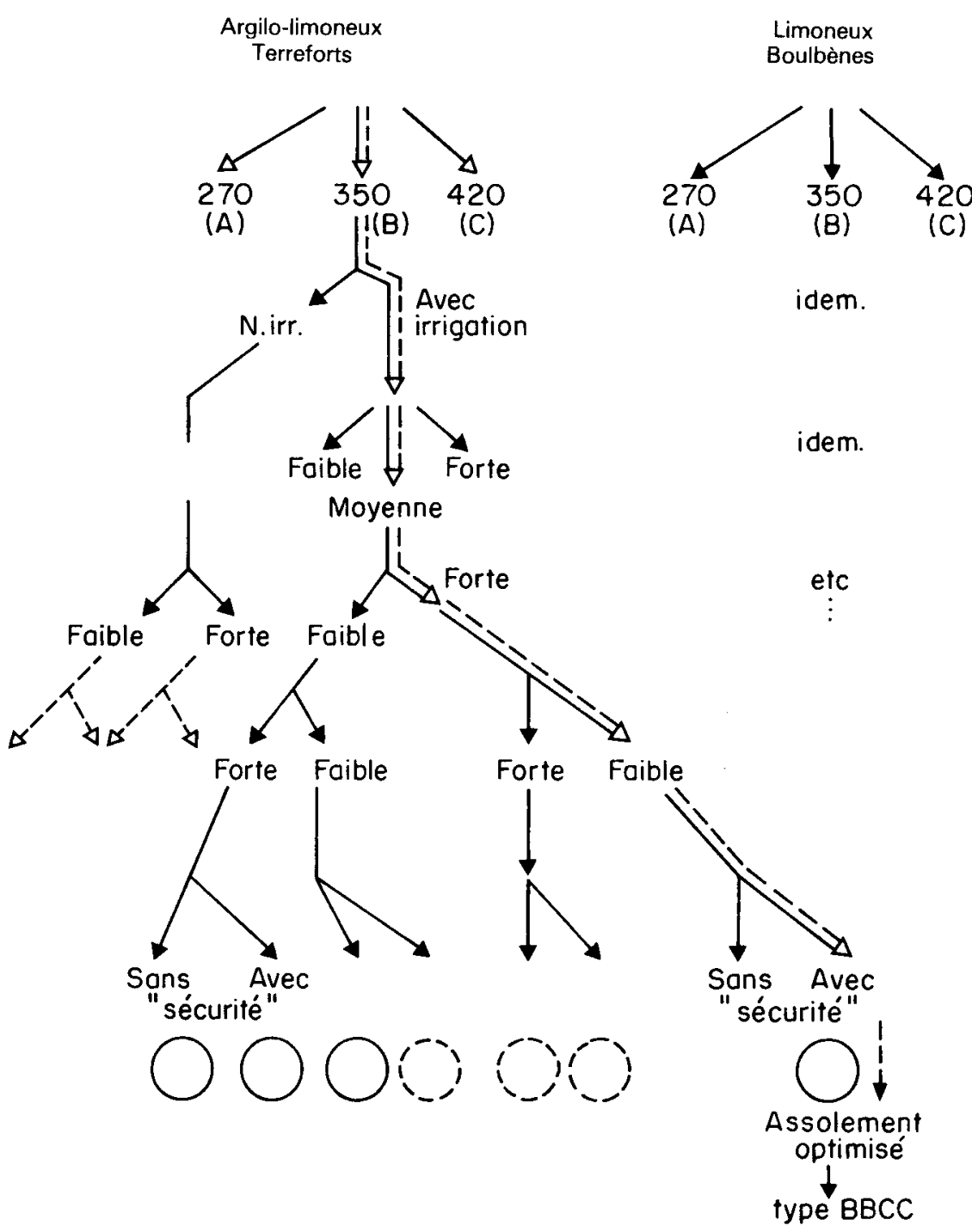

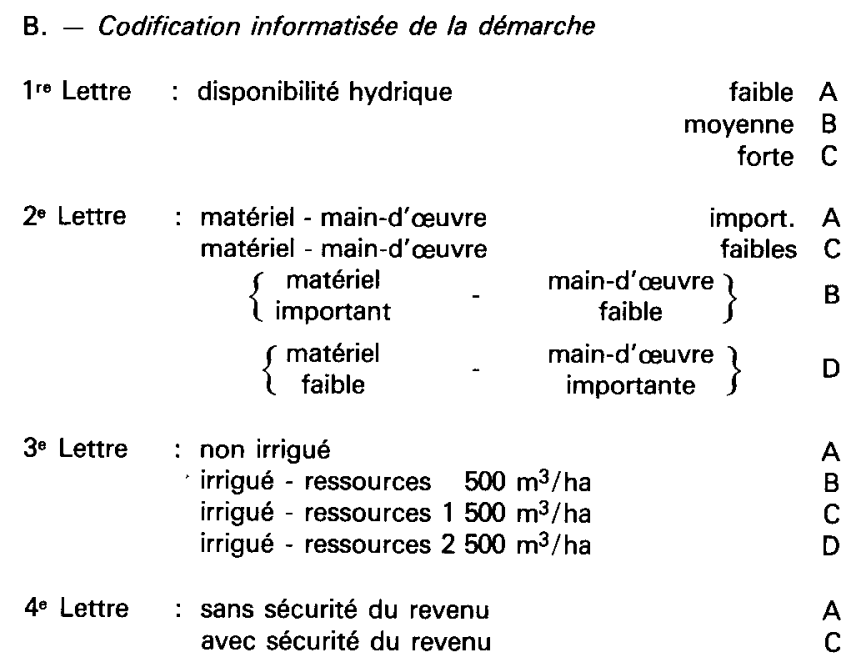

Elaboration d'assolements optimisés : cheminements possibles dans le modele : exemple de solution (pour 1 hypothèse de prix).
Example of one land use optimisation : possible paths through the model (for one assumed price). 
Hypothèses de départ

\begin{tabular}{lrl}
\hline \multicolumn{2}{r}{ Solution BBCC } & $\begin{array}{c}\text { Code : } \\
\text { ef. fig. } 4\end{array}$ \\
\hline TERREFORT & $350 \mathrm{~mm}$ \\
CAPITAL & $4000 \mathrm{~F}$ \\
UTH & $21 \mathrm{~h} / \mathrm{ha}$ \\
EAU & $150 \mathrm{~mm}$ \\
REV & $3000 \mathrm{~F}$ \\
\hline \hline
\end{tabular}

Rendement technico-économique

(à l'ha assolé)

FONC ECO : $5883 \mathrm{~F} / \mathrm{ha}$ (marge brute)

CAPITAL : $1499 \mathrm{~F} / \mathrm{ha}$

MAIN D'OEUVRE : $12.67 \mathrm{~h} \mathrm{C} \quad \mathrm{HI} \quad \mathrm{KL}$

EAU APPORTÉE : $65 \mathrm{~mm}$

SOLE
Pointes de travaux :

$\mathrm{C}-1 / 04-30 / 04$

$\mathrm{H}-1 / 08-15 / 08$

I $-16 / 08-31 / 08$

$\mathrm{K}-1 / 10-31 / 10$

$\mathrm{L}-1 / 11-30 / 11$

Eléments de fonctionnement de l'assolement optimisé à l'ha assolé

Proportion de chaque culture toutes rotations confondues

\begin{tabular}{ll}
\hline \hline \multicolumn{1}{c}{ ASSOLEMENTS } \\
\hline BLÉ & .34 \\
COLZA & .08 \\
ORGE & .00 \\
POIS & .08 \\
MAÏS & .06 \\
SORGHO & .07 \\
TOURNESOL & .00 \\
SOJA & .37 \\
\hline
\end{tabular}

Proportion de chaque culture par activité (précédent-rotation)

\begin{tabular}{|c|c|c|}
\hline \multicolumn{3}{|c|}{ CULTURES par activité } \\
\hline $\mathrm{BPB}$ & (49.3 QX- 0 MM-0 INT) & .081 \\
\hline BJB & (49.3 QX- 0 MM-0 INT) & .258 \\
\hline CBB & (21.0 QX- $0 \mathrm{MM}-0$ INT) & .081 \\
\hline PCB & (35.0 QX- 0 MM-0 INT) & .081 \\
\hline MJB3 & (98.0 QX-170 MM-5 INT) & .057 \\
\hline SBB & (53.1 QX- 0 MM-0 INT) & .067 \\
\hline SBB1 & (70.5 QX-100 MM-3 INT) & .002 \\
\hline JBB2 & (33.7 QX-150 MM-4 INT) & .189 \\
\hline $\mathrm{JJB} 2$ & (33.7 QX-150 MM-4 INT) & .057 \\
\hline JSB2 & (33.7 QX-150 MM-4 INT) & .069 \\
\hline JMB2 & (33.7 QX-150 MM-4 INT) & .057 \\
\hline
\end{tabular}

Légende :

BPB : Blé après pois.

BJB : Blé après soja.

CBB : Colza après blé.

PCB : Pois après colza.

MJB3 : Maïs après soja ; irrigation intensive.

SBB : Sorgho après blé non irrigué.

SBB1 : Sorgho après blé (1) ; irrigation période critique.

JBB2 : Soja après blé ; irrigation modérée.

JJB2 : Soja après soja ; irrigation modérée.

JSB2 : Soja après sorgho ; irrigation modérée.

JMB2 : Soja après maîs ; irrigation modérée.

(1) Peut être considérée comme négligeable.
Proportion des diverses rotations dans l'assolement

\begin{tabular}{llll}
\hline & & \multicolumn{1}{c}{ ROTATIONS } \\
JJM & .17 & SOJA-SOJA-MAÏS & 1 \\
JB & .38 & SOJA-BLÉ & 2 \\
JBS & .21 & SOJA-BLÉ-SORGHO & 3 \\
CPB & .24 & COLZA-POIS-BLÉ & 4 \\
\hline \hline
\end{tabular}

Schématisation de l'assolement et des cultures en rotations

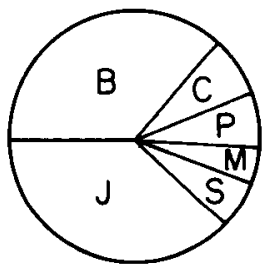

Assolement

( $\mathrm{P}-$ pois ou féveroles)

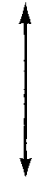

(Parcellaire)
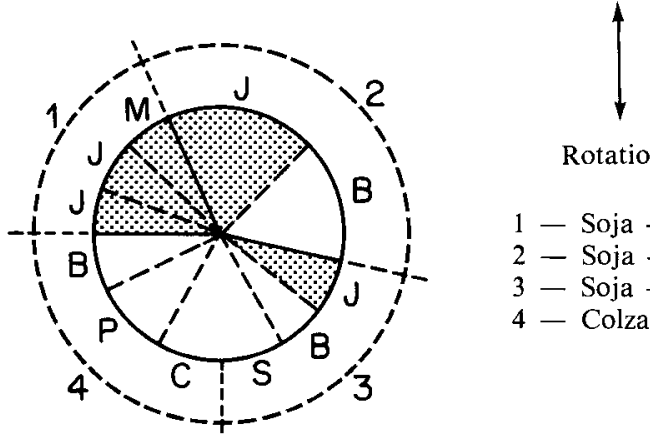

Rotations

1 - Soja - Soja - Maïs

2 - Soja - Blé

3 - Soja - Blé - Sorgho

4 - Colza - Pois - Blé 


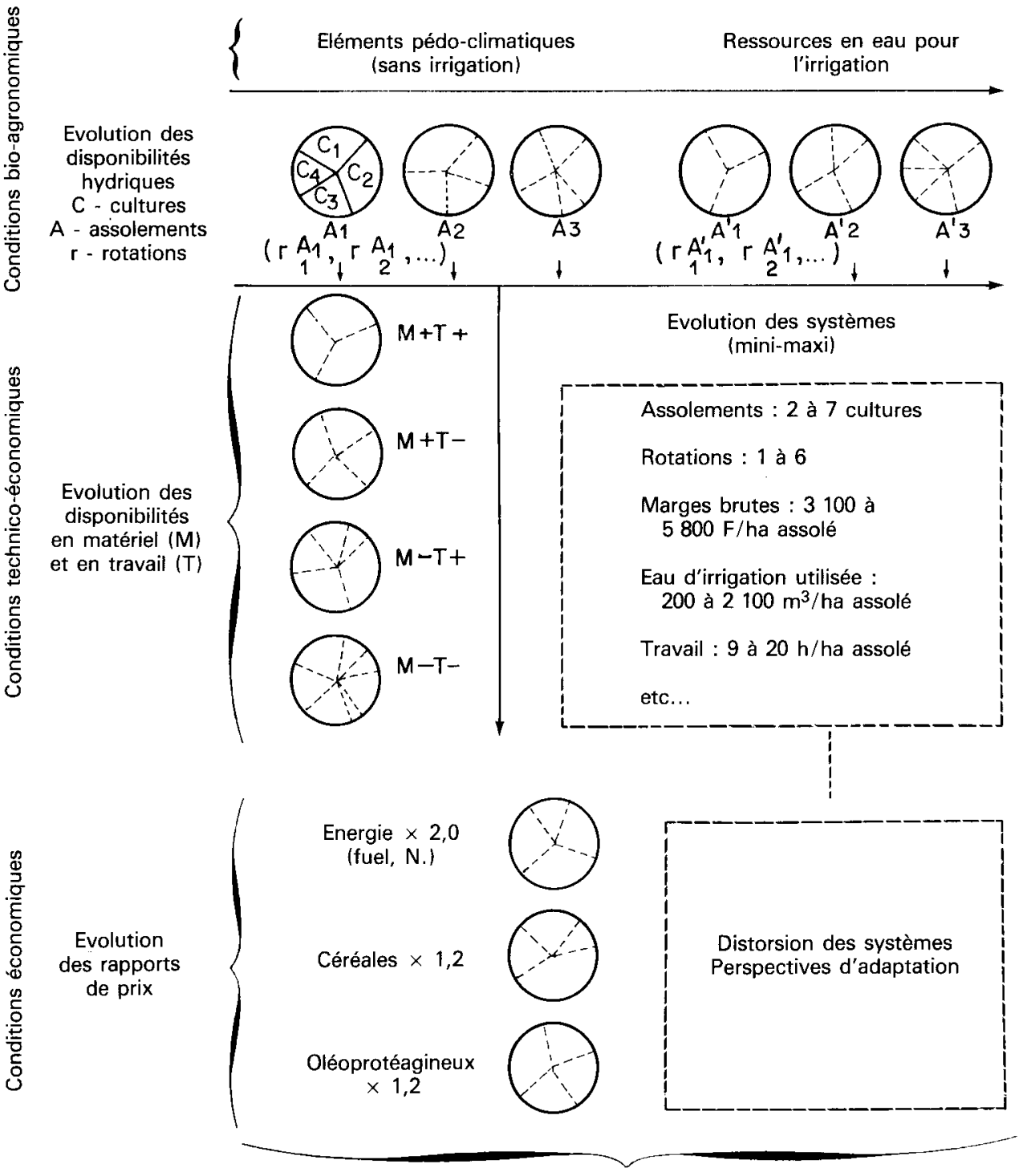

Analyse des possibilités d'évolution et d'adaptation

Figure 6

Perspectives d'utilisation des résultats (exemple schématique).

l'on dispose de systèmes d'irrigation hautement automatisés. On peut cependant noter que, vers $28 \mathrm{~h}$ de disponibilité/ha/an, l'utilisation du matériel (C) s'accroît plus rapidement que l'augmentation des marges brutes pour lesquelles la tendance à atteindre un palier s'amorce.

A noter la non-utilisation totale de la main-d'œuvre disponible (D) du fait de l'impossibilité de transférer les heures inutilisées en périodes calmes pendant les périodes chargées en travaux, au-delà de $12 \mathrm{~h}$ /jour. En fait, notre calcul ne tient compte que du temps occupé aux interventions techniques qui ne représente en général que 50 p. 100 du temps total d'activité (approche à la parcelle, charroi, entretien, gestion, etc...). Pour les mêmes raisons, la totalité du matériel disponible ne peut être utilisé.

Les résultats vérifient ainsi la relative stabilité des assolements optimisés proposés par le modèle vis-à-vis des fluctuations d'un des paramètres discriminant dans la détermination des assolements.
Prospects for using the results (schematic example).

\section{CONCLUSION}

Nous avons voulu réaliser une étude à la fois synthétique et prospective d'assolements optimisés sous les aspects technico-économiques :

- synthétique, en ordonnant et interprétant la masse complexe des données pluriannuelles qui caractérisent les expérimentations au champ, grâce à une collaboration interdisciplinaire ;

- prospective, en traitant les solutions indépendamment des structures d'exploitation et en les exprimant à l'unité de surface assolée. Cette démarche nous laisse ainsi la possibilité de simulation de fluctuations économiques ou de choix possible au niveau d'exploitations agricoles.

Cette démarche s'appuie sur des références expérimentales pluriannuelles, des itinéraires techniques réellement pratiqués, raisonnés au niveau des rotations culturales et avec contrôle de la qualité de travail 
Evolution

de la marge brute des proportions

M.B f/ho

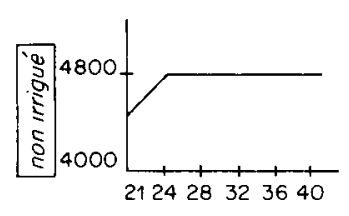

M. 8 f/ho

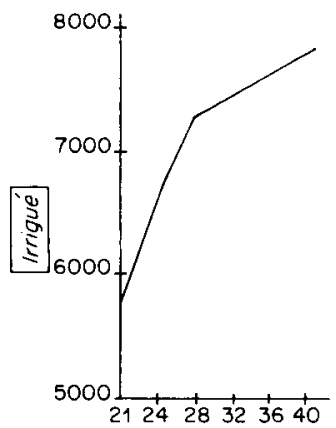

Evolution des cultures dans la sole

Evolution de l'utilisation du matériel

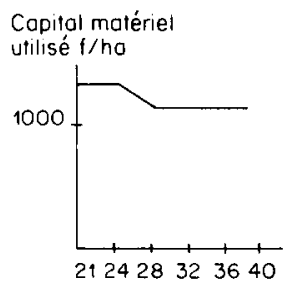

212428323640

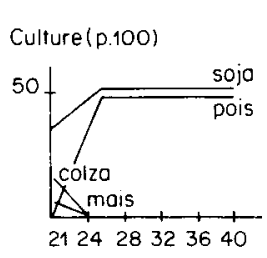

212428323640 2124283236 40 heures
disponibles/ho

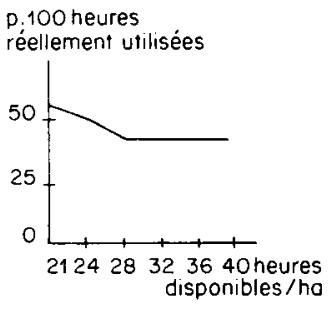

de l'utilisation

de la main-d'œuvre

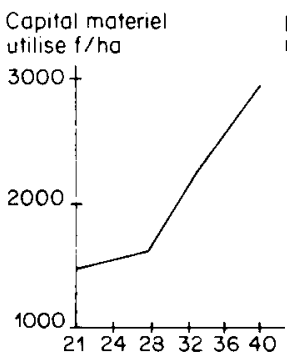

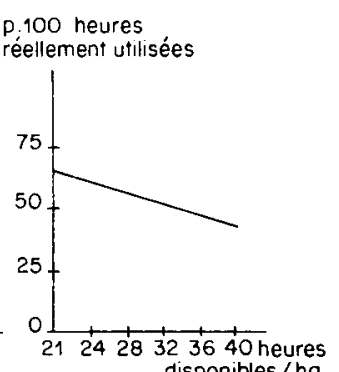

Figure 7

Evolution technico-économique des assolements selon une disponibilité variable en main-d'œuvre de 21 à 40 heures par hectare et par an dans le cas de capital matériel élevé (exemple pour sol argilolimoneux, disponibilité hydrique naturelle $350 \mathrm{~mm}$, non irrigué et irrigué avec ressources en eau non limitantes).

réalisé (HUTTER, 1982). De plus, nous avons précisé le fonctionnement de rotations au champ par l'acquisition d'éléments explicatifs, tels que arrière-effets, bilans minéraux et hydriques, évolution de la flore adventice, du potentiel infectieux, etc... qui ont fait, par ailleurs, l'objet de diverses autres publications. Le passage de la dimension temporelle (rotation) à la dimension spatiale (assolement) a été réalisé par la formulation d'hypothèses inspirées d'enquêtes en exploitations agricoles qui devrait ouvrir un large champ exploratoire d'assolements optimisés et pérennisés par des successions de cultures agronomiquement et techniquement fiables. Nous pensons préciser ainsi des choix économiques (CORDONNIER, 1976) ou sectoriels, obtenus, soit par comparaison des marges brutes des différentes cultures (Chambre d'Agriculture Haute-Garonne - SUAGER, 1981), soit issus de simulation budgétaire (fichier Régional déjà cité). Enfin, nous voulions disposer d'un modèle fournissant des solutions concrètes au niveau des assolements ainsi que des éclairages de mise en valeur d'un milieu (SEBILlotTe, 1982).

Toutefois, cette démarche doit encore être perfectionnée car elle présente encore des lacunes :

- un défaut de précision lié notamment aux ajustements statistiques successifs en même temps qu'un excès de rigueur dans le choix final de l'assolement dû à la programmation linéaire et basé sur la maximisation de la fonction économique. Ceci peut éliminer des solutions intéressantes au voisinage de l'optimum :

- la limitation actuelle à la sole des grandes cultu-
Technical and economical evolution of land use according to variable labour availability from 21 to $40 \mathrm{~h}$ per hectare and per year, with high level of capital equipment (example for clay soil, natural water availability $350 \mathrm{~mm}$, not irrigated or irrigated in the presence of non-limiting water resources.

res à graines commercialisables et l'impasse importante qui subsiste en système de polyculture élevage, avec des résultats ni exhaustifs ni définitifs ;

- une nécessité d'actualisation permanente des entrées techniques, agronomiques et économiques du modèle et une nécessité de perfectionner constamment celui-ci afin de faire progresser cette démarche ;

- l'utilisation d'une seule stratégie de production pour toutes les cultures, tout en sachant que plusieurs niveaux d'intensification sont pratiqués dans une même exploitation agricole selon les cultures et les parcelles. Ce problème de niveau d'intrants représente une importante lacune dans la compréhension des systèmes de culture et il constitue le thème principal d'une nouvelle expérimentation (MARTY et al., 1981) ;

- une certaine lourdeur de la technique utilisée (nécessité de disposer d'un puissant ordinateur) à cause de la quantité des informations disponibles ;

- les résultats obtenus ne peuvent passer tels quels directement dans la pratique du fait de la " désincarnation " voulue de leur expression à l'unité de surface assolée. Il importe de continuer les actions en cours permettant de préciser le degré de conformité de ces perspectives avec la réalité des exploitations agricoles (structures, échelles de surface parcellaires, etc...). Toutefois, cette démarche peut se révéler un outil performant en complément d'amont des approches de recherches de systèmes de culture par exemple par le système " Explor " : approche par tâtonnement (IGER, 1972) en fournissant comme base de départ aux processus de simulation un assolement optimisé.

Enfin, il apparaît que l'étude des systèmes de culture à partir d'assolements et de rotations soit moins 
développée que les études sectorielles. Pourtant, il s'avère indispensable « à une époque où les progrès fondamentaux offrent des moyens d'actions ponctuels sur les végétaux et sur leurs peuplements » de lancer " des approches synthétiques, progressives » et de « recentrage pour agir sur le terrain » (CAUDERON, 1983).

Grâce à l'aide et aux collaborations dont nous avons bénéficié, c'est ce que nous avons tenté de réaliser dans cette étude dont nous présenterons prochainement les résultats technico-économiques plus détaillés.

Reçu le 25 octobre 1983. Accepté le 21 mai 1984.

\section{REMERCIEMENTS}

Nous devons spécialement remercier pour leur aide efficace et leurs conseils :

Le Comité Technique du Contrat programme Irrigation DGRSTI.N.R.A. et notamment son Président R. BLANCHET.

J.-M. Boussard et I. Foulhouze du Laboratoire d'Economie et de Sociologie Rurale I.N.R.A. de Paris.

P. Charon de la Compagnie d'Aménagement des Coteaux de Gascogne.

C. Lavernhe de la Chambre Régionale d'Agriculture MidiPyrénées.

\section{RÉFÉRENCES BIBLIOGRAPHIQUES}

Attonaty J. M., 1969. Aspects économiques de l'irrigation en grande culture dans les régions subhumides. Laboratoire d'Economie Rurale, I.N.R.A. Grignon, $44 \mathrm{p}$.

Blanchet R., Maertens C., Marty J.-R., Gelfi N., 1966. Influence des constituants minéraux de quelques types de sol sur leurs propriétés physiques et leurs possibilités culturales. Bull. Assoc. fr. Etud. Sol, 17-40.

Blanchet R., Marty J.-R., 1973. Prévisions de plans de fertilisation à l'échelle de diverses rotations en culture irriguée ou non. Bull. Assoc. fr. Etud. Sol, 137-250.

Bosc M., Blanchet R., 1976. Réponses de quelques cultures à la fumure phosphatée dans un sol diversement enrichi. C. R. Acad. Agric., 62, 724-734.

Boussard J.-M., 1980. Programmation linéaire et système de culture. Séminaire C.E.E. : Méthodologie d'étude des systèmes de culture, 7-9 mai 1980, Toulouse, 57-63.

Boussard J.-M., 1981. Données techniques et données économiques en matières de production agricole. Séminaire C.E.E. : Optimisation des intrants dans un système de culture, 15-16 janvier 1981, Toulouse, 110-118.

Cabelguenne M., 1981. Facteurs technico-économiques de la valorisation de l'irrigation. Le cas des grandes cultures d'été dans le SudOuest de la France. Thèse de doctorat de $3^{\mathrm{e}}$ cycle en Etudes Rurales Intégrées, 214 p. Université de Toulouse le Mirail, Institut de Géographie D. Foucher.

Cabelguenne M., Marty J.-R., Hilaire A., 1982. Comparaison technico-économique de la valorisation de l'irrigation par quatre cultures d'été (maïs, soja, sorgho, tournesol). Agronomie, 2 (6), $567-576$.

CACG, 1981. Evolution des rendements de maïs irrigué de la Région de l'Astarac. Direction du Développement Service des Etudes du Milieu, 33 p.

CACG, 1981. L'irrigation en Gascogne. Opinion des agriculteurs (contrat de programme DGRST), $88 \mathrm{p}$.

CACG, 1982. Résultats de 1980 des exploitations utilisant l'irrigation. Panel d'exploitation, 103 p.

Capillon A., Sebillotte M., 1980. Etude des systèmes de production des exploitations agricoles. Une typologie. Caribbean seminar on farming systems. Research Methodology, Pointe à Pitre (Guadeloupe), 85-109.

Cauderon A., 1983. Techniques de production dans les systèmes de cultures à base de céréales. Evolution en France 1950-1980. Réflexion sur l'avenir. Cultivar, supp. au $\mathrm{n}^{\circ}$ 158, 2-23.

C.E.E. (Communauté Economique Européenne), 1980. Méthodologie d'étude des systèmes de culture. Agrimed, sous-groupe grandes cultures, 7, 8, 9 mai 1980, Toulouse, $251 \mathrm{p}$

C.E.E. (Communauté Economique Européenne), 1981. Optimisation des intrants dans un système de culture. Agrimed, sous-groupe grandes cultures, Toulouse, $158 \mathrm{p}$.

Chambre d'Agriculture Haute-Garonne, Service Utilité Agricole et de Dévelopement (S.U.A.D.). Panorama climatique. Essais et démonstration. C. R. annuels, 1976 à 1981.
Chambre d'Agriculture Haute-Garonne, Centre de Gestion et d'Economie Rurale, S.U.A.G.E.R., 1979-1981. Etude comparative des marges brutes. C. R. annuels.

Chambre Régionale d'Agriculture Midi-Pyrénées, 1981 (1). L'irrigation dans le canton de Montaigu de Quercy en Tarn-et-Garonne. Opinion des agriculteurs, $46 \mathrm{p} .+$ annexes. (2) Enquête : comportement des agriculteurs de l'A.S.A. de la Vallée de la Lèze et proposition pour une démarche de développement, $28 \mathrm{p}$. + annexes.

Cochard B., 1971. Dates de labour, qualité du travail, jours disponibles. Bull. Assoc. fr. Etud. Sol, 25-38.

Commission des Communautés Européennes, 1983 COM (83) 260 FINAL. Programme cadre des activités scientifiques et techniques communautaires, 1984-1987. Comm. Commission au Conseil et au Parlement Européen, $91 \mathrm{p}$

Cordonnier P., 1976. Aspects économiques relatifs à la rentabilite de l'irrigation du mais. Laboratoire d'Economie Rurale I.N.R.A. Grignon, $14 \mathrm{p}$.

Cresson E., 1982. Etats Généraux du Développement Agricole, Paris, 3-5.

Delphin J.-E., Specty R., 1981. Arrière-effets irrigation, rotations, restitution des pailles d'un essai de 10 ans sur une culture d'homogénéisation (maïs irrigué). C. R. Acad. Agric., 67 (2), 176-185.

Dent J. B., Anderson J. R., 1971. Systems Analysis in Agricultural management. A Wiley International Edition Australia, 394 p.

F.A.O., 1980. Réponses des rendements à l'eau. Bulletin d'irrigation et de drainage, $\mathrm{n}^{\circ} 33,325 \mathrm{p}$

Fichier Régional de Références des Cultures et des Animaux, 1980 Comité Fédératif Régional des Centres de Gestion de MidiPyrénées.

Foulhouze I., Boussard J.-M., Nassef M., 1981. La programmation linéaire dans le contrat programme "Irrigation» de la Station d'Agronomie I.N.R.A. Toulouse. Laboratoire Economie et Sociologie Rurales, I.N.R.A. Paris, 33 p.

Hilaire A., 1980. Incidence de la nutrition azotée sur la production d'un blé d'hiver dans différentes rotations culturales. Thèse Institut National Polytechnique de Toulouse, 118 p.

Hutter W., 1982. Itinéraires de la préparation du sol et des rendements des cultures dans un dispositif expérimental avec rotations. C. R. Acad. Agric., 68 (16), 1272-1278.

I.G.E.R. (Institut de Gestion et d'Economie Rurale), 1972. Système Explore. Principe de la simulation. Approche par tâtonnement. 2 ronéotypes, 13 p. et 39 p. Direction des Services techniques, Service Gestion.

I.T.C.F. (Institut Technique des Céréales et des Fourrages), 1984. C. R. d'essais, Bureau Régional Zone Sud-Ouest. Brochure ronéo, $26 \mathrm{p}$.

Kaan Y., Rellier J.-P., 1980. Traitement sur ordinateur des données du dispositif expérimental d'Auzeville : présentation critique. Séminaire C.E.E. : Méthodologie d'Etude des Systèmes de culture, Toulouse, 7, 8, 9 mai 1980, 207-224. 
Labonne M., 1980. Systèmes de production et politique agricole. Caribbean seminar on farming systems. Research Methodology, Pointe à Pitre (Guadeloupe), 241-249.

Le Floch D., 1976. Caractéristique de production et techniques culturales de quelques légumineuses à grains (féverole, lupin, pois, soja) dans les conditions du bassin de Rennes. Sciences Agronomiques, Ecole Nationale supérieure agronomique, Rennes (France), 121-135.

Lefort G., Sebillotte M., 1964. Construction d'un programme linéaire pour l'étude du meilleur système de production d'une exploitation agricole et de son adaptation aux aléas climatiques. C. R. Acad. Agric., 56, 239-250.

Marty J.-R., Fioramonti S., 1970. Comparaison de diverses rotations sur sol limoneux mal structuré. Effet améliorant des cultures fourragères. Ann. agron., 21 (3), 269-286.

Marty J.-R., Hilaire A., 1974. Références technico-économiqıes. Publication Station d'Agronomie Toulouse, Document diffusion multiple. 2 brochures, 33 et $68 \mathrm{p}$.

Marty J.-R., Hilaire A., 1979. Effets de divers précédents culturaux sur la conduite et la production du blé d'hiver : tentative de vue d'ensemble des effets liés à l'état du sol, aux reliquats d'azote et aux résidus de récolte. Agrochimica, 123 (2), 152-163.

Marty J.-R., Hutter W., 1975. Expérimentations sur rotations de cultures irriguées ou non. Station d'Agronomie I.N.R.A. Toulouse, $21 \mathrm{p}$.

Marty J.-R., Cabelguenne M., Merrien A., 1983a. Perspectives sur la place du colza en assolements du Sud-Ouest, $6^{e}$ Congrès International sur le Colza, Paris, $6 \mathrm{p}$.

Marty J.-R., Hilaire A., Cabelguenne M., 1982a. Perspectives sur la place des oléoprotéagineux dans les assolements du Sud-Ouest de la France. C. R. Acad. Agric., 16, 1262-1271.

Marty J.-R., Hilaire A., Cabelguenne M., 1983b. Eléments de raisonnement des systèmes de cultures adaptés aux conditions de sol et de climat et à la valorisation des moyens utilisés (exemple du SudOuest de la France), Colloque C.E.N.E.C.A., Paris.

Marty J.-R., Hutter W., Rellier J.-P., 1981. Projet de programme de recherches expérimentales sur l'optimisation des intrants dans des rotations avec céréales et oléoprotéagineux avec ou sans irrigation. Séminaire C.E.E. : Optimisation des intrants dans un système de culture, Toulouse, 15-16 janvier, 119-131.

Marty J.-R., Cabelguenne M., Puech J., Hilaire A., 1982b. Irrigation et évolution des systèmes de culture dans la région toulousaine. Bull. tech. Inform., $n^{\circ}$ spécial : Fertilité du milieu et agriculture, 370-372, 563-571.

Marty J.-R., Hilaire A., Puech J., Cabelguenne M., 1982c. Le blé d'hiver en rotations et assolements de grande culture du Sud-Ouest : influence des conditions de milieu, des techniques et moyens mis en œuvre. Séminaire I.N.R.A., Département d'Agronomie, mars 1982, Vichy, 80-89.
Marty J.-R., Puech J., Maertens C., Blanchet R., 1975. Etude expérimentale de la réponse de quelques grandes cultures à l'irrigation. C. R. Acad. Agric., 61 (10), 560-575.

Puech J., Marty J.-R., 1981. Valorisation de lirrigation par les grandes cultures du Sud-Ouest (mais, sorgho, soja, tournesol). C. R. de fin d'études d'une recherche financée par la Délégation Générale à la recherche scientifique et technique (D.G.R.S.T.), $52 \mathrm{p}$.

Reboul C., Mamoun M., Desbrosses B., 1979. Météorologie et jours disponibles pour les travaux des champs. Résultats statistiques en Ile de France, I.N.R.A., Service Economie et Sociologie Rurales, $176 \mathrm{p}$.

Rellier J.-P., 1981. Etude statistique des facteurs de rendement du maïs-grain à partir de références expérimentales multispaciales. Conséquences sur l'optimisation de quelques intrants. Séminaire C.E.E. : Optimisation des intrants dans un système de culture. 15-16 janvier, Toulouse, 81-97.

Remy J.-C., Hebert J., 1977. Le devenir des engrais azotés dans le sol. C. R. Acad. Agric., 11, 700-712.

Ribeyre C., Manichon H., 1980. Le tournesol dans ses principales régions de production en France; analyse de sa situation pour en dégager les voies de développement en France. INA-PG, GEARA, Chaire d'Agronomie, $53 \mathrm{p}$.

Sebillotte M., 1978. Itinéraires techniques et évolution de la pensée agronomique. C. R. Acad. Agric., 11, 901-914.

Sebillotte M., 1982. Les systèmes de culture. Réflexions sur l'intérêt et l'emploi de cette notion à partir de l'expérience acquise en région de grande culture. Séminaire I.N.R.A., Département d'Agronomie, Vichy, mars 1982, 63-79.

Seguy, 1980. Une expérience d'élaboration de systèmes de production adaptés à la petite agriculture du Maranhäo (Brésil). Caribbean seminar on farming systems. Research methodology, Pointe à Pitre (Guadeloupe), 339-351.

SOGREAH (Société Grenobloise d'Etude d'Aménagement Hydraulique), Direction départementale de l'Agriculture (Haute-Garonne), Aménagement Hydraulique du Bassin de la Garonne.

- 1965. Opportunité des aménagements hydro-agricoles dans la vallée de l'Ariège : Etude Agro-socio-économique, 77 p. + annexes. Etudes des Aménagements hydro-agricoles, 75 p. + annexes. Rapport Rpa 9071.

- 1967. Etude socio-économique des vallées principales, Rapport Rpa 9865,156 p. + annexes.

- 1968. Définition des aménagements hydro-agricoles des vallées principales du Bassin de la Garonne, Rapport Rpa 9835, $42 \mathrm{p}+$ annexes. 